\title{
Estimated Benefits of Incremental Suppression of Covid-19 Spread
}

\author{
Chi Keung Woo', Kang Hua Cao ${ }^{2 *}$, Yun Lyndon Liu ${ }^{3}$, Qiqi Li ${ }^{4}$ \\ ${ }^{1}$ Department of Asian and Policy Studies, Education University of Hong Kong, Hong Kong, China \\ ${ }^{2}$ Department of Economics, Hong Kong Baptist University, Hong Kong, China \\ ${ }^{3}$ School of Accounting and Finance, Hong Kong Polytechnic University, Hong Kong, China \\ ${ }^{4}$ School of Communication, Hong Kong Baptist University, Hong Kong, China \\ Email: ckiwoo@eduhk.hk, *kanghuacao@hkbu.edu.hk, yun-lyndon.liu@polyu.edu.hk, aki.li.qiqi@gmail.com
}

How to cite this paper: Woo, C.K., Cao, K.H., Liu, Y.L. and Li, Q.Q. (2020) Estimated Benefits of Incremental Suppression of Covid-19 Spread. Open Access Library Journal, 7: e6645.

https://doi.org/10.4236/oalib.1106645

Received: July 23, 2020

Accepted: August 18, 2020

Published: August 21, 2020

Copyright (C) 2020 by author(s) and Open Access Library Inc.

This work is licensed under the Creative Commons Attribution International License (CC BY 4.0).

http://creativecommons.org/licenses/by/4.0/

\section{(c) (i) Open Access}

\begin{abstract}
Estimated benefits are necessary for a cost benefit analysis of Covid-19 suppression. We propose a stock-market-based approach to estimate the benefits of incremental suppression of Covid-19's spread that will last till no new cases are recorded for 14 days, the projected incubation period of Covid-19. This approach's empirical implementation uses a) total capitalization of 14 market indices for large cap stocks; and b) an index's estimated elasticity of cumulative confirmed cases (CCC) obtained from a panel data analysis of 727 daily observations in the period of 01/21/2020-04/03/2020. Our estimated benefits of a hypothetical $10 \%$ reduction in CCC due to incremental suppression are statistically significant ( $p$-value $<0.05$ ), ranging from US $\$ 0.76$ billion for Singapore to US $\$ 70$ billion for the US. As the S \& P 500 index's capitalization is $70 \%-80 \%$ of the US total market capitalization, the adjusted US benefit estimate is up to US $\$ 100$ billion. Finally, we verify that these estimated benefits are empirically reasonable.
\end{abstract}

\section{Subject Areas}

Public Economics, Health Economics

\section{Keywords}

Covid-19, Suppression Benefit, Stock Markets

\section{Introduction}

Estimated benefits are necessary in a cost benefit analysis of Covid-19 suppression, thus raising a substantive question: what are the estimated benefits of Covid-19's incremental suppression? This question's relevance is underscored by 
the increasingly strong actions taken in late March of 2020 by the US and European governments to suppress Covid-19's surging spread [1].

In this paper, we estimate the benefits of incremental suppression that result in a hypothetical 10\% reduction in Covid-19's cumulative confirmed cases (CCC) for 14 stock market locations in Asia, Europe, North America, and Australia. ${ }^{1}$ If these estimated benefits turn out to be relatively small, they suggest that incremental suppression should not occur.

First detected in China in early December $2019,{ }^{2}$ Covid-19 is officially a pandemic as of 03/12/2020 [1]. While Covid-19's spread has peaked in China by mid-February 2020, it continues to surge in other countries, as exemplified by the US, Italy, Germany, Spain, France and UK, which in descending order had the highest numbers of cumulative confirmed cases (CCC) on 03/31/2020 outside China [1]. ${ }^{3}$

In response to Covid-19's spread, governments have taken various suppression actions, including national border closures, business and school shutdowns, public event cancelations, limits on social gathering, home isolations, mandatory quarantines, local and international travel restrictions, and reduced service of public transportation [1]. Such actions curb economic activities that accelerate the spread of a viral disease [2].

As Covid-19 is recent, we can only find one study on benefits of suppression. Specifically, [3] (p. 6) estimates that Covid-19's total cost sans suppression in the US exceeds US $\$ 13.2$ trillion, comprising medical cost, value of lost productivity and fatality cost based on value of statistical life [4]. The total cost estimate for a 78-week suppression period is US $\$ 15.8$ billion, exceeding those for shorter periods [3] (p. 7). Hence, "it may be optimal to stop [suppression] before a vaccine becomes available" [3] (p. 7). ${ }^{4}$

Accepting that suppression will likely continue in the summer months of 2020 , we propose a stock-market-based approach to estimate the benefit of incremental suppression that will last till no new cases are recorded for 14 days, the projected incubation period of Covid-19. ${ }^{5}$ Since our focus is incremental suppression's estimated benefits, it differs from [3]'s focus of whether suppression should end before a vaccine becomes available.

Recognizing Covid-19's damaging effect on stock prices [5], our approach presumes that a firm's stock price measures the present value (PV) of future profits [6]. Our approach has two parts. Part 1 explains the benefit calculation based on

${ }^{1}$ The US number of CCC on 04/03/2020 is 213,600 [1]. The hypothetical $10 \%$ reduction in CCC equals 21,360 confirmed cases, thus easing the highly stressed healthcare system in the US.

${ }^{2}$ https://www.theguardian.com/world/2020/mar/20/chinese-inquiry-exonerates-coronavirus-whistle blower-doctor-li-wenliang

${ }^{3}$ Daily Covid-19 updates are available at: https://coronavirus.jhu.edu/map.html.

${ }^{4} \mathrm{~A}$ safe and effective vaccine is at least a year away

(https://www.theguardian.com/world/2020/apr/03/when-will-a-coronavirus-vaccine-be-ready). In the meantime, Covid-19's spread will likely subside when a large percentage (e.g., 80\%) of the surviving population have developed immunity, reducing the chance of an uninfected person becoming infected (https://time.com/5810454/coronavirus-immunity-reinfection/).

${ }^{5}$ https://www.npr.org/sections/health-shots/2020/04/01/824903684/the-science-behind-a-14-day-qua rantine-after-possible-covid-19-exposure 
a stock market index's (“index's" for short hereafter) capitalization and CCC elasticity $\mathcal{E}=$ percentage change in the index due to 1 -perecent change in CCC. Part 2 is a double-log regression, whose estimation yields an index's CCC elasticity. As the number of cumulative deaths is driven by the number of CCC, ${ }^{6}$ an index's increase due to a decline in CCC captures the life-saving effect of incremental suppression on an index.?

To develop our approach's empirics, we conduct a panel data analysis of 14 daily indices for large cap stocks during 01/21/2020-04/03/2020. ${ }^{8}$ These stock markets are chosen based on Covid-19 spread's geographic variations over time. Our three key findings are as follows. First, an index's estimated CCC elasticity is small, ranging from -0.010 to -0.057 . Second, a hypothetical $10 \%$ reduction in CCC caused by incremental suppression is estimated to increase market capitalization by US $\$ 0.76$ billion for Singapore to US\$70 billion for the US. An adjustment to reflect a large cap index's underrepresentation of a stock market magnifies these benefit estimates. For the US, the adjusted benefit estimate is up to US\$100 billion. Finally, we verify that our estimated benefits are empirically reasonable. To the best of our knowledge, these findings are new, chiefly because of our research focus and data recentness.

The rest of this paper proceeds as follows. Section 2 states our benefit formula, regression specification, testable hypotheses, and data construction. Section 3 presents our initial exploration, regression results, estimated benefits, and final checks. Section 4 concludes by recapping our key findings and stating the caveats of our paper.

\section{Materials and Methods}

\subsection{Benefit Formula}

Let $I_{k}$ denote index $k$ for $k=1, \cdots, 14$. Suppose $I_{k}$ 's elasticity with respect to market $k$ 's CCC is $\varepsilon_{k}=\partial \ln \left(I_{k}\right) / \partial \ln \left(\mathrm{CCC}_{k}\right)<0$. The percentage increase in market $k$ 's capitalization in response to $\Delta \ln \left(\mathrm{CCC}_{k}\right)<0$ caused by incremental suppression is:

$$
Y_{k}=\varepsilon_{k} \times \Delta \ln \left(\mathrm{CCC}_{k}\right)>0 \text {. }
$$

Let $V_{k}$ denote index $k$ 's capitalization. The dollar increase in $V_{k}$ is:

$$
\Delta V_{k}=V_{k} \times Y_{k}>0 \text {, }
$$

\footnotetext{
${ }^{6}$ This is because confirmation typically precedes death, unless a Covid-19 patient dies before detection, a relatively rare event due to increased Covid-19 testing of symptomatic people and asymptomatic people who have been in an area of a Covid-19 outbreak or had close contact with a confirmed Covid-19 patient.

${ }^{7}$ To see this point, consider a simple function $y=f(x, z)$. If $z=g(x)$, it can be written as $y=h(x)$.

${ }^{8}$ There are three reasons supporting our index choice. First, these widely available indices are commonly used for measuring market returns. Second, they are highly correlated with the total market indices. Using the US as an illustrative example, the S \& P 500 index is highly correlated $(r>0.95)$ with the total market index Wilshire 5000. Finally, using large cap indices results in conservative benefit estimates that mitigate criticisms of overestimation. For the US example, the S \& P 500 index's capitalization is $70 \%-80 \%$ of the US total market capitalization. To counter the argument that the benefit estimate based on the S \& P 500 index is unreasonably low, we adjust the US estimate based on the S \& P 500 index's share of the US total market capitalization.
} 
which is a conservative estimate when $V_{k}$ is less than market $k$ 's total capitalization. For the US example, the S \& P 500 index's capitalization is $70 \%-80 \%$ of the US total market capitalization. Hence, if $\mathrm{D} V_{k}$ is based on the S \& $\mathrm{P} 500$ index, its understatement can be as much as $43 \%[=(1 / 0.7)-1]$.

\subsection{Regression Specification}

Applying Equation (1) requires an estimate for $\varepsilon_{k}$, which can be obtained from a panel data analysis based on the following double-log regression with random error $\mu_{k t}[9]^{9}$ :

$$
\ln \left(I_{k t}\right)=\Sigma_{j} \alpha_{k} \ln \left(X_{k t}\right)+\text { Fixed effects }+\mu_{k t} ; ;^{10}
$$

where $I_{k t}$ is market $k$ 's index on day $t$. Whether Equation (3) is empirically plausible is best judged by the regression results reported in Section 3.2 below.

There are three reasons for our choice of a double-log specification. First, $\alpha_{k}=\partial \ln \left(I_{k t}\right) / \partial \ln \left(X_{k t}\right)$ is an elasticity, measuring an index's percentage change due to a 1-percengt change in $X_{k t} \equiv\left(1+\right.$ number of $\mathrm{CCC}_{k}$ on day $\left.t\right)$. Justifying $X_{k t}$ 's definition is avoidance of missing data caused by $\ln (0)$ being undefined. ${ }^{11}$ Since $\mathrm{CCC}_{k}$ is well above 200 for all $k$ by $03 / 31 / 2020$ [1], $\alpha_{k}$ is numerically identical within two digits to $\mathcal{E}_{k}{ }^{12}$ We expect $\alpha_{k}<0$ because of Covid-19's damaging effect on stock prices [5]. To identify $\alpha_{k}$, we assume $\alpha_{k}$ is a linear function of binary indicators for market location. The fixed effects are controls for market location, day of week and month of year. ${ }^{13}$

Second, it circumvents the problem of population differences because a country with a large population tends to have higher CCC than a country with a small population.

Third, it resolves the scale differences among indices, as exemplified by the US's S \& P 500 index that was below 3000 and Hong Kong's HSI that was above 20,000 during our chosen sample period of 01/21/2020-04/03/2020, see Section 2.5 below.

We end this section by noting that Equation (3) does not use $\ln (1+$ number of cumulative deaths) as an additional regressor because it is highly correlated $(r>$ $0.9)$ with $\ln \left(X_{k t}\right)$, causing severe multicollinearity that leads to imprecise and counter-intuitive coefficient estimates. Further, Equation (3) does not include government announcements of relief packages because these announcements are driven by Covid-19's spread severity, which is already captured by $\ln \left(X_{k t}\right)$.

\footnotetext{
${ }^{9}$ We decide not to use a CAPM-based approach (e.g., [5]) that does not readily produce the elasticity estimates necessary for computing $\mathrm{D} V_{k}$.

${ }^{10}$ This regression is spurious when its residuals are non-stationary [7]. Hence, after estimating Equation (3), we used the panel unit root test proposed by [8] to reject the hypothesis that the regression residuals follow a random walk.

${ }^{11}$ The number of CCC in January 2020 is zero for European countries [1].

${ }^{12}$ To see this point, consider the simple example of $\ln (y)=b \ln (1+n)$ where $n$ is a positive integer. As $d \ln (y) / d \ln (n)=b[n /(1+n)], b=0.995 \times d \ln (y) / d \ln (n)$ at $n=200$.

${ }^{13}$ When estimating Equation (3), we performed the Hausman test [9] (Chapter 10) to reject the hypothesis that Equation (3) should be based on random effects.
} 


\subsection{Testable Hypotheses}

Denoting equation (3) as Model 0 , we use the $F$-test to test three hypotheses for a better understanding of an index's CCC responsiveness:

- $H_{1}$ : All markets have the same elasticity, which implies Model 1 with $\alpha_{k}=\alpha$ for all $k$.

- $H_{2}$ : Fixed effects do not matter, which implies Model 2 that excludes fixed effects.

- $H_{3}$ : Identical elasticity and no fixed effects, which implies Model 3 that restricts $\alpha_{k}=\alpha$ for all $k$ and excludes fixed effects.

\subsection{Data Construction}

To construct our panel data, we use 14 daily indices for large cap stocks listed in Figure 1 and daily CCC data provided by Johns Hopkins University (JHU). Our sample period is $01 / 21 / 2020-04 / 03 / 2020$, whose beginning date is when JHU first published CCC data and ending date reflects the data available at the time of our writing. The resulting sample contains 727 daily observations, a newly created Covid-19 dataset that differentiates our paper from [3] and studies on prior pandemics such as SARS and Ebola (e.g., [10] and [11]).

\section{Results}

\subsection{Initial Exploration}

To presage Covid-19's damaging effects, Figure 1 portrays the cumulative losses suffered by the 14 chosen markets. China's loss is noticeably lower than those of other countries, likely because China's earlier Covid-19 outbreak has already dampened China's stock market.

For the seven countries most affected by Covid-19 as of 04/03/2020: the US, China, Italy, Germany, Spain, France and UK, Figure 2 shows that their indices tend to decline with CCC. It also highlights that China's Covid-19 spread peaked in mid-February 2020 when those of the other six countries began to accelerate, painting a time profile that aids our estimation of an index's CCC elasticity.

Table 1 contains our sample's descriptive statistics and correlation. While in-

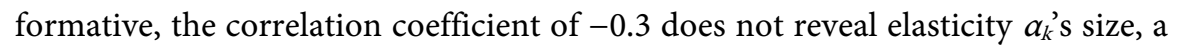
task to be accomplished by the regression results reported below.

\subsection{Regression Results}

Table 2 reports our regression results, leading to the following inferences. First, Model 0 's within $R^{2}$ value is 0.85 , suggesting Equation (3) reasonably fits the index data. Further, Model 0 's coefficient estimates are all statistically significant ( $p$-value $<0.05$ ) and have correct signs. Hence, Model 0 is an empirically plausible representation of the data generating process for the 14 indices.

Second, Model 0's estimated elasticities range from -0.010 for China to 
-0.057 for Taiwan. The $\alpha_{12}$ estimate for the US is -0.028 , implying a $10 \%$ decrease in CCC tends to increase the S \& P 500 index by $0.28 \%$. The remaining elasticity estimates tell a similar story.

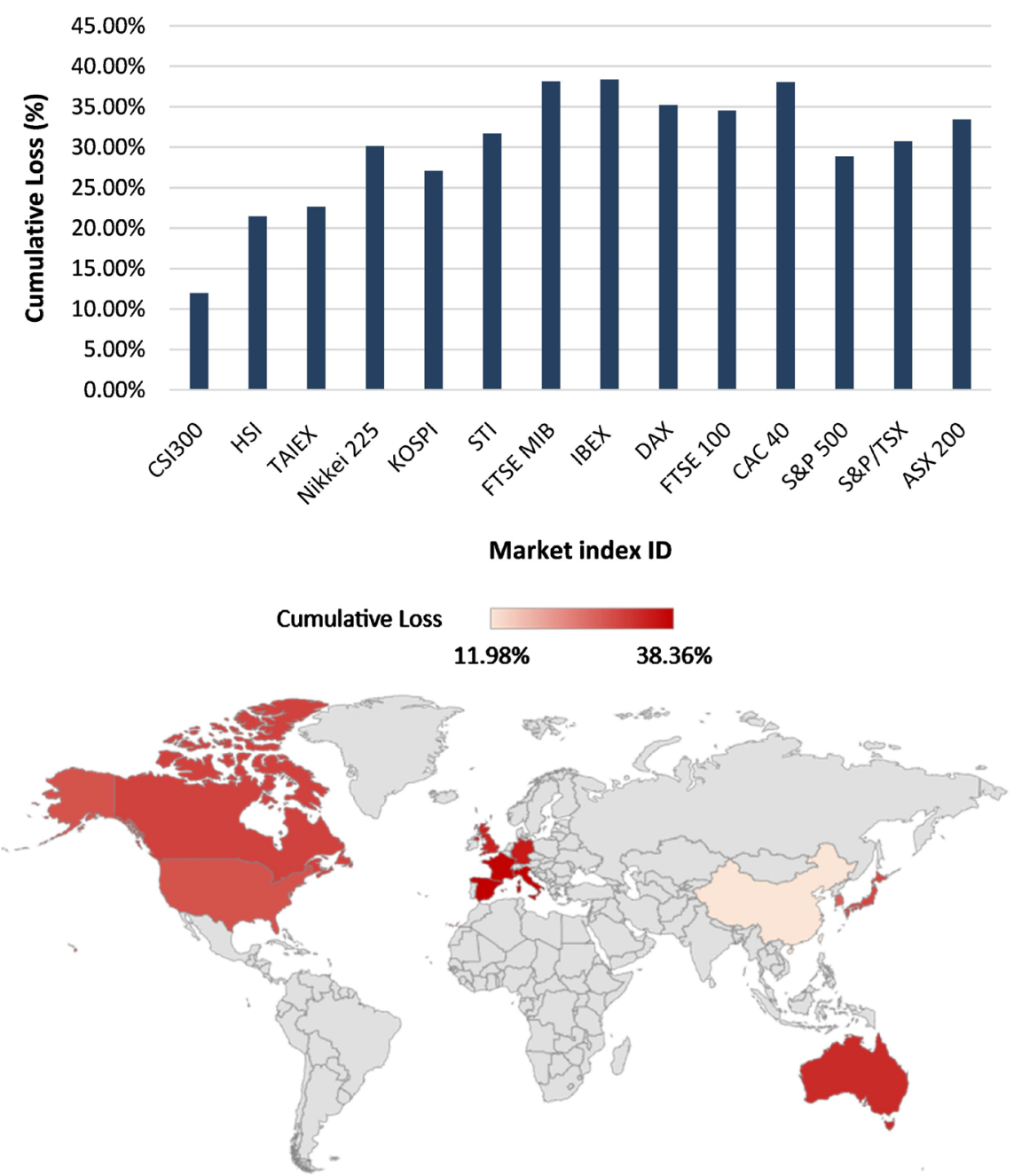

Notes: 1) Cumulative loss $=\ln$ (closing index level on $01 / 20 / 2020)-\ln ($ closing index level on 04/03/2020). 2) The 14 market indices are: a) Asia: CSI300 (China), HSI (Hong Kong), TAIEX (Taiwan), STI (Singapore), Nikkei 225 (Japan), KOSPI (South Korea); b) Europe: DAX (Germany), FTSE 100 (UK), CAC 40 (France), IBEX (Spain), FTSE MIB (Italy); c) North America: S \& P 500 (US), S \& P/TSX (Canada); and d) ASX 200 (Australia).

Figure 1. Cumulative losses by market for the period of 01/21/2020-04/03/2020 that matches the availability of Covid-19 data published by Johns Hopkins University.

Table 1. Descriptive statistics and correlations based on 727 daily observations in the sample period of 01/21/2020-04/03/2020.

\begin{tabular}{cccccc}
\hline Variable [expected market effect] & Mean & Standard deviation & Minimum & Maximum & Correlation coefficient \\
\hline $\ln$ (daily stock market index) & 8.95 & 0.80 & 7.28 & 10.25 & 1.00 \\
$\ln (1+$ number of cumulative confirmed cases) $[-]$ & 5.21 & 3.47 & 0.00 & 12.53 & -0.30 \\
$\ln ($ MSCI total market index) & 6.96 & 1.23 & 4.24 & 9.40 & 0.25 \\
\hline
\end{tabular}


US
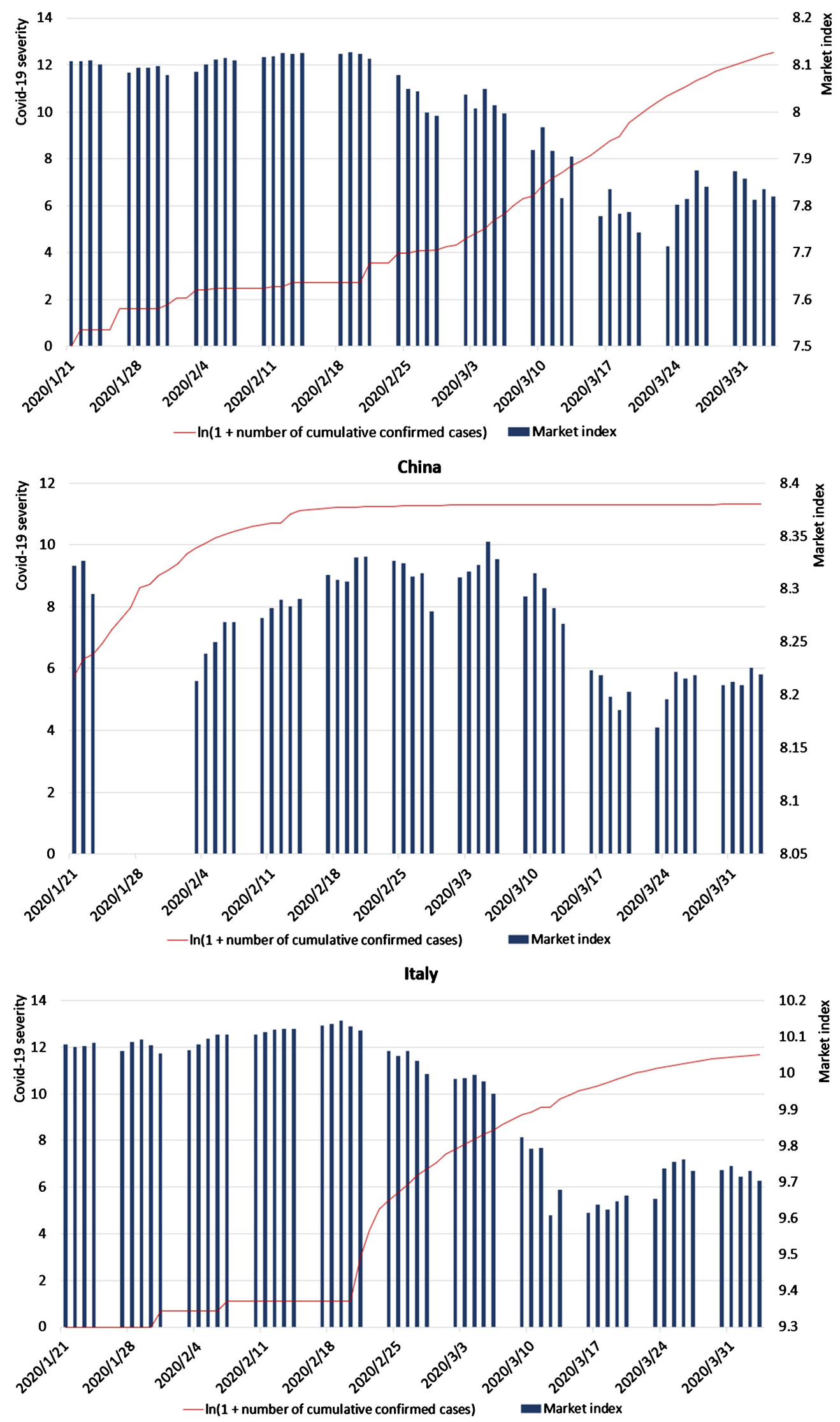

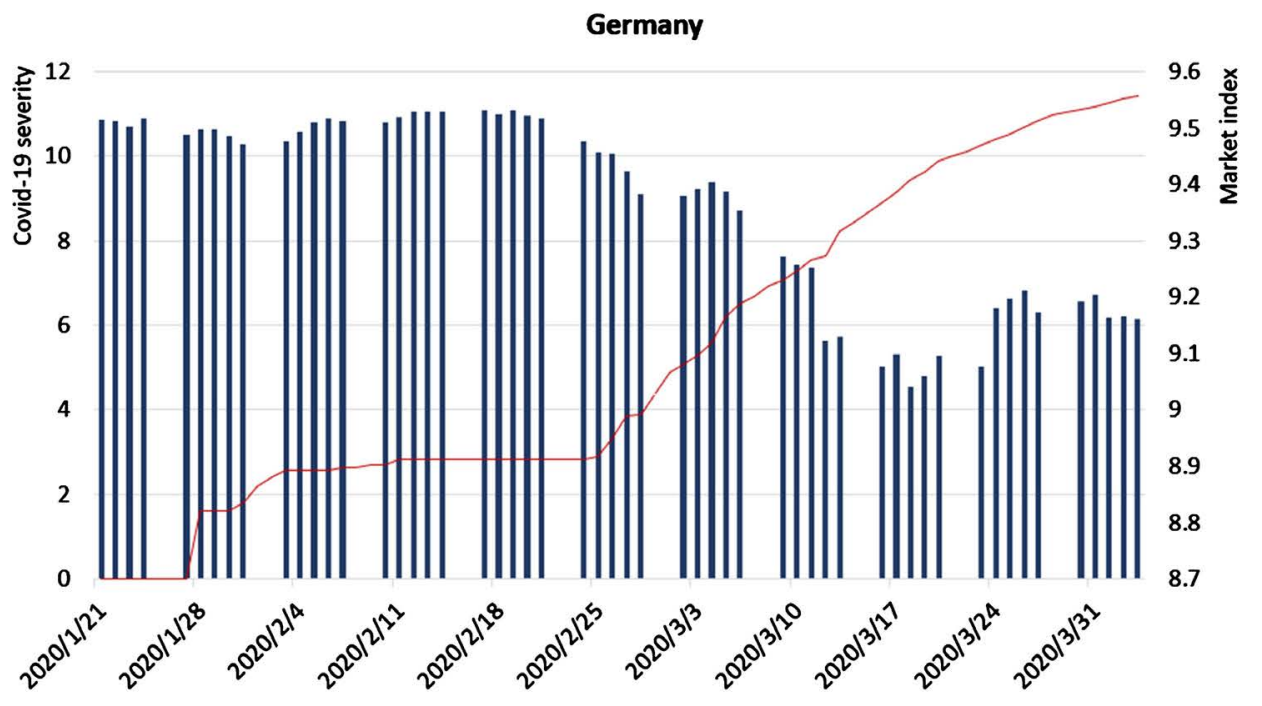

- $\ln (1+$ number of cumulative confirmed cases) Market index

Spain
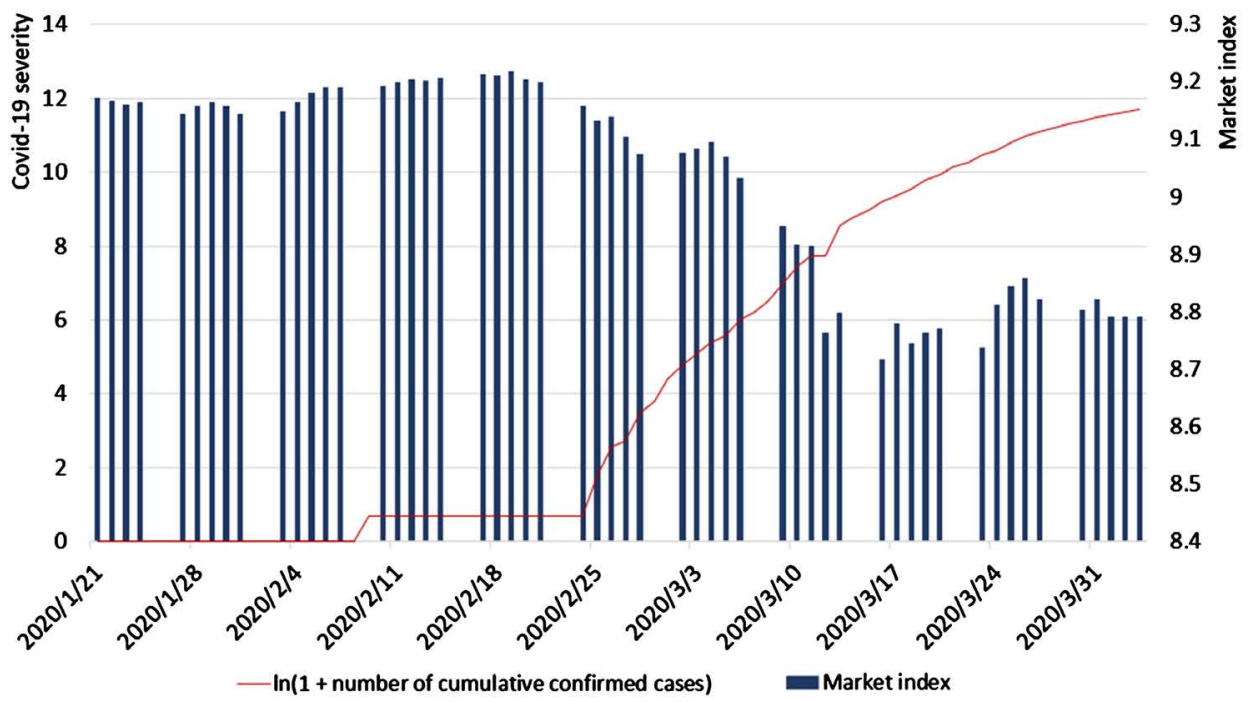

France
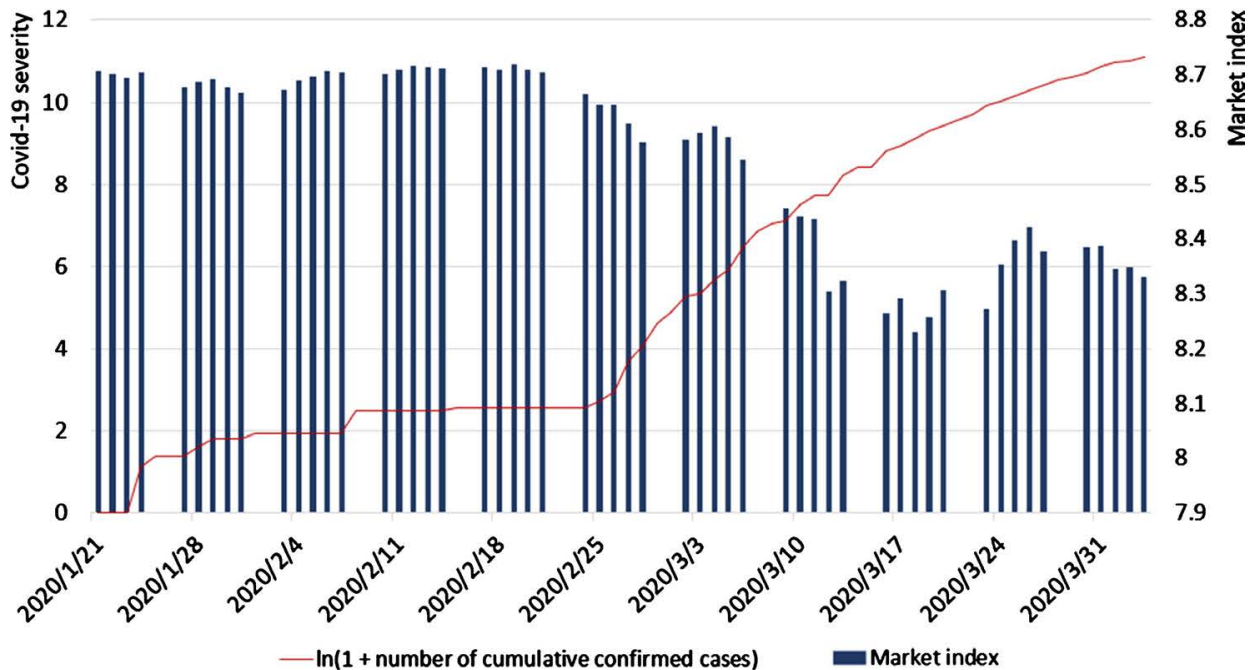
UK

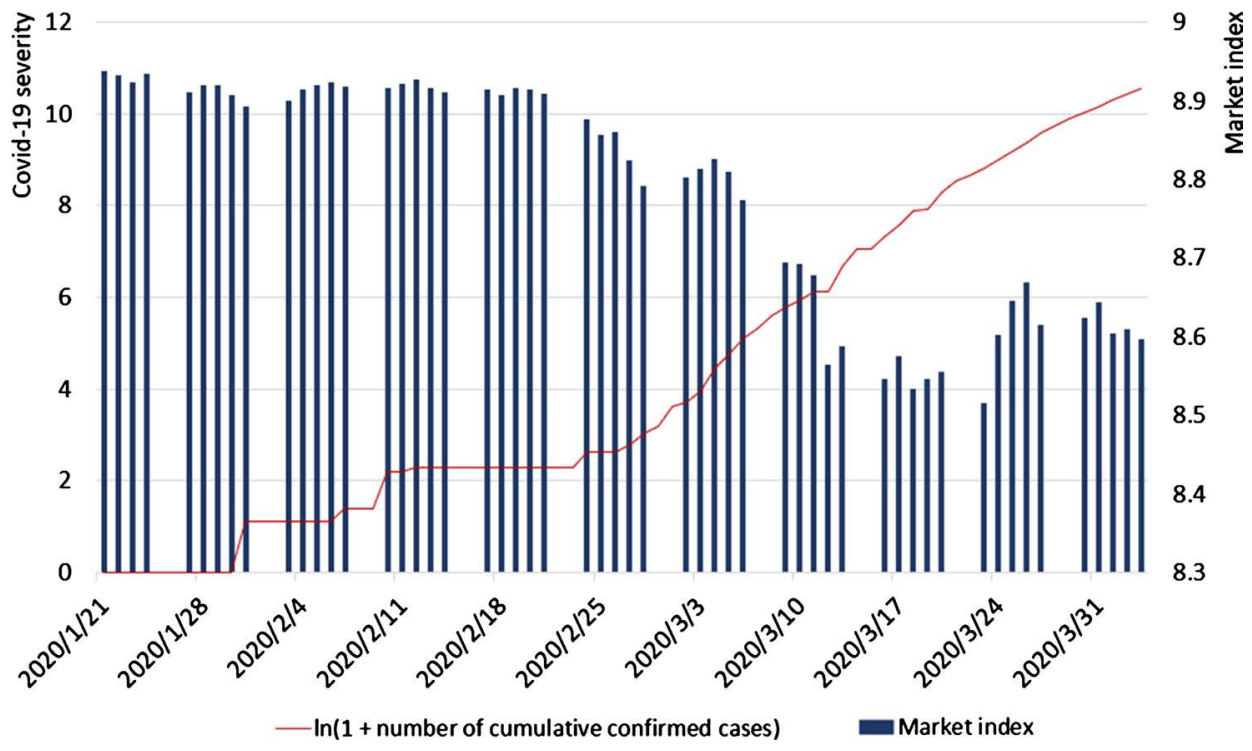

Figure 2. Graphic representation of country-specific natural-log values of market index and (1 + number of cumulative confirmed cases).

Finally, the $F$-test results decisively ( $p$-value $<0.0001$ ) reject $H_{1}$ to $H_{3}$. A close inspection of the elasticity estimates produced by Models 1 to 3 leads to the following remarks. First, Model 1's estimated elasticity is -0.033 , matching the mid-point of the range produced by Model 0 . Second, Model 2 yields statistically significant elasticity estimates with wrong signs, implying that it should not be used for our benefit calculation. Third, Model 3's elasticity estimate is -0.068 , much larger in size than Model 0's. Hence, we decide not to use Model 3 to avoid overstating the benefit estimates.

\subsection{Estimated Benefits}

To estimate the benefits of a hypothetical $10 \%$ decrease in CCC, we use each index's capitalization on $04 / 03 / 2020$ as the reference case of no incremental suppression. As market capitalization on 04/03/2020 could have reacted to government announcements of increasingly strong actions, our estimated benefits correspond to additional anti-Covid-19 actions beyond those already announced.

Figure 3 portrays the $\Delta V_{k}$ estimates based on Model 0's elasticity estimates reported in Table 2. These $\Delta V_{k}$ estimates range from US $\$ 0.76$ billion for Singapore to US $\$ 70$ billion for the US. Since the S \& P 500 index's capitalization is $70 \%-80 \%$ of the US total market capitalization, we multiply our US estimate of $\$ 70$ billion by 1.43 to derive an adjusted estimate of up to US $\$ 100$ billion, which is far less than the $\sim$ US $\$ 13$ trillion benefit inferred from [3]. ${ }^{14}$ This is understandable because our US benefit estimate is based on incremental suppression, whereas the inferred estimate is based on a comparison of two cost scenarios: without suppression vs. with suppression.

$\overline{{ }^{14}}$ US $\$ 13.2$ trillion cost without suppression - US $\$ 15$ billion cost with suppression $=\sim$ US $\$ 13$ trillion. 
Table 2. Results from a panel data (fixed effects) analysis of large cap index data based on 727 daily observations in the sample period of 01/21/2020-04/03/2020.

\begin{tabular}{|c|c|c|c|c|}
\hline Variable [coefficient] & $\begin{array}{c}\text { Model 0: Equation } \\
\text { (3) that has varying } \\
\text { elasticities }\left(\alpha_{k} \neq \alpha\right) \\
\text { and includes fixed } \\
\text { effects }\end{array}$ & $\begin{array}{l}\text { Model } 1 \text { under } \\
H_{1}: \text { Identical } \\
\text { elasticity }\left(\alpha_{k}=\alpha\right)\end{array}$ & $\begin{array}{c}\text { Model } 2 \\
\text { under } H_{2} \text { : No } \\
\text { fixed effects }\end{array}$ & $\begin{array}{c}\text { Model } 3 \text { under } H_{3} \text { : } \\
\text { Identical elasticity } \\
\left(\alpha_{k}=\alpha\right) \text { and no } \\
\text { fixed effects }\end{array}$ \\
\hline$R^{2}$ : within & 0.8531 & 0.8306 & & \\
\hline$R^{2}$ : between & 0.0132 & 0.1239 & & \\
\hline$R^{2}$ : overall & 0.0168 & 0.0779 & 0.7896 & 0.0882 \\
\hline $\ln (1+$ number of cumulative confirmed cases $):$ not country-specific $[\alpha]$ & & -0.0332 & & -0.0684 \\
\hline $\ln (1+$ number of cumulative confirmed cases $)$ : China $\left[\alpha_{1}\right]$ & -0.0102 & & -0.0847 & \\
\hline $\ln (1+$ number of cumulative confirmed cases $):$ Hong Kong $\left[\alpha_{2}\right]$ & -0.0348 & & 0.1912 & \\
\hline $\ln (1+$ number of cumulative confirmed cases $)$ : Taiwan $\left[\alpha_{3}\right]$ & -0.0573 & & 0.0165 & \\
\hline $\ln (1+$ number of cumulative confirmed cases $)$ : Japan $\left[\alpha_{4}\right]$ & -0.0463 & & 0.1232 & \\
\hline $\ln (1+$ number of cumulative confirmed cases $)$ : Korea $\left[\alpha_{5}\right]$ & -0.0283 & & -0.2156 & \\
\hline $\ln (1+$ number of cumulative confirmed cases $)$ : Singapore $\left[\alpha_{6}\right]$ & -0.0538 & & -0.2473 & \\
\hline $\ln (1+$ number of cumulative confirmed cases $)$ : Italy $\left[\alpha_{7}\right]$ & -0.0334 & & 0.0657 & \\
\hline $\ln (1+$ number of cumulative confirmed cases $):$ France $\left[\alpha_{8}\right]$ & -0.0385 & & -0.0981 & \\
\hline $\ln \left(1+\right.$ number of cumulative confirmed cases): Germany $\left[\alpha_{9}\right]$ & -0.0376 & & 0.0072 & \\
\hline $\ln (1+$ number of cumulative confirmed cases $)$ : Spain $\left[\alpha_{10}\right]$ & -0.0344 & & -0.0372 & \\
\hline $\ln (1+$ number of cumulative confirmed cases $):$ UK $\left[\alpha_{11}\right]$ & -0.0352 & & -0.0736 & \\
\hline $\ln (1+$ number of cumulative confirmed cases $):$ US $\left[\alpha_{12}\right]$ & -0.0283 & & -0.1591 & \\
\hline $\ln (1+$ number of cumulative confirmed cases $)$ : Canada $\left[\alpha_{13}\right]$ & -0.0436 & & 0.0598 & \\
\hline $\ln (1+$ number of cumulative confirmed cases $):$ Australia $\left[\alpha_{14}\right]$ & -0.0526 & & -0.0984 & \\
\hline$p$-value of the $F$-statistic statistic for testing $H_{m}$ for $m=1,2,3$ & & $<0.0001$ & $<0.0001$ & $<0.0001$ \\
\hline
\end{tabular}

Notes: 1) For brevity, this table omits the estimated intercept and fixed effects that are highly statistically significant $(p$-value $<0.01) .2)$ The CCC elasticities are labelled according to their continental locations: Asia's elasticities are $\alpha_{1}$ to $\alpha_{6}$, Europe's $\alpha_{7}$ to $\alpha_{11}$, North America's $\alpha_{12}$ and $\alpha_{13}$, and Australia's $\alpha_{14}$. 3) We use robust standard errors clustered by market that are heteroskedasticity-autocorrelation-consistent to determine the coefficient estimates' statistical significance. 4) Coefficient estimates in bold are statistically significant $(p$-value $<0.05)$ and have correct signs. Coefficients estimates in italic are statistically insignificant ( $p$-value $>0.05$ ) and have wrong signs. Coefficients estimates in italic are statistically significant $(p$-value $<0.05)$ and have wrong signs.

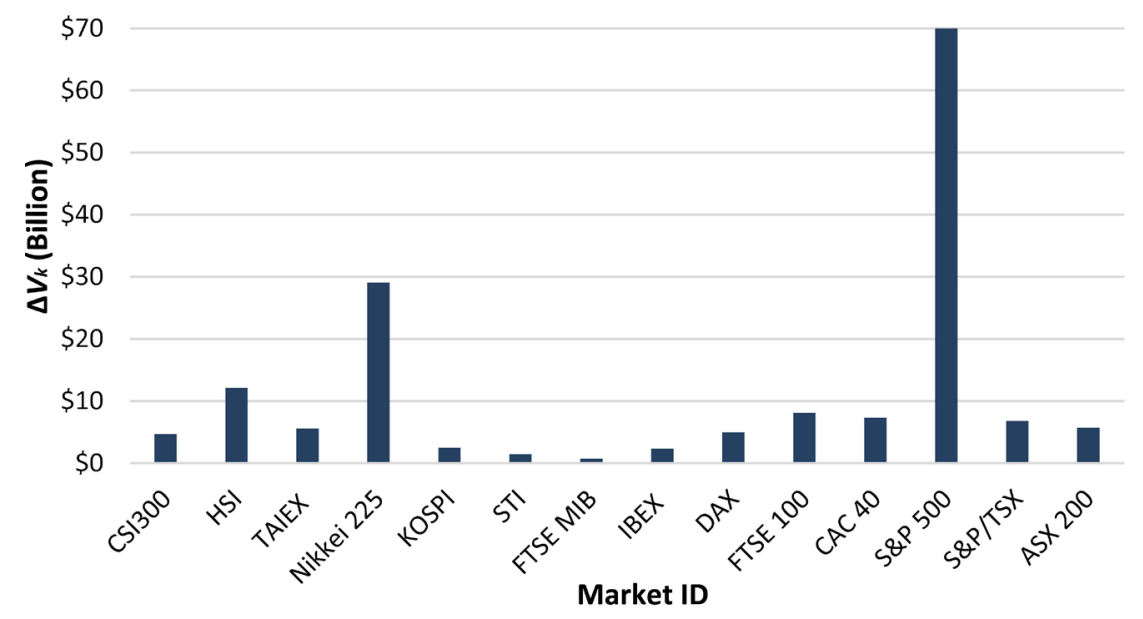

Notes: (1) The benefit calculation is based on equations (1) and (2) in Section 2.1. (2) The elasticity estimates are those reported in Table 2.

Figure 3. Estimated benefits (based on big cap indices' capitalization) of a hypothetical $10 \%$ reduction in the number of cumulative confirmed cases. 


\subsection{Final Checks}

We perform three final checks of the estimated benefits reported in the last section, finding them empirically reasonable.

First, we use the estimated version of Equation (3) to calculate the increase in $S \& P$ index's capitalization under the what-if scenario of no Covid-19 outbreak. This calculation yields $\Delta V_{12}=-V_{12} \times a_{12} \times \ln \left(X_{12}\right)=$ US $\$ 8.77$ trillion, where $V_{12}$ $=\mathrm{S} \& \mathrm{P} 500$ capitalization on $04 / 03 / 2020=\$ 24.7$ trillion, $a_{12}=\alpha_{12}$ estimate $=$ -0.0283 , and $\ln \left(X_{12}\right)=\ln (1+$ number of CCC in the US on $04 / 03 / 2020)=12.53$. The US $\$ 8.77$ trillion increase is equivalent to a $26 \%[=8.87 /(8.87+24.7)] \mathrm{cu}-$ mulative loss in total capitalization since $02 / 21 / 2020$, which is reasonably close to the $29 \%$ cumulative loss shown in Figure 1.

Second, we multiply $\Delta V_{12}=$ US $\$ 8.77$ trillion by the 1.43 adjustment factor to account for the S \& P 500 index's market underrepresentation. The adjusted $\Delta V_{12}$ is US $\$ 12.54$ trillion, comparable to the $\sim$ US $\$ 13$ trillion estimated benefit of suppression inferred from [3]. Thus, our estimated increase in total market capitalization under the scenario of no Covid-19 outbreak resembles the benefit of suppression inferred from an economic cost comparison, notwithstanding that these two numbers are derived from very different methodologies and data sources.

Finally, we re-estimate Equation (3) using the MSCI total market index data which are much less frequently used by financial news media than the big cap stock index data. Except for China with a correlation coefficient of 0.84, the MSCI data are highly correlated $(r>0.95)$ with the large cap index data. Table 3 reports the re-estimation results that are comparable to those reported in Table 2, lending support to our expectation that an index's CCC elasticity estimate should only be modestly sensitive to the choice between large cap index data and total market index data. A good case in point is that the newly found CCC elasticity estimate for the US is -0.0287 , almost identical to the corresponding estimate of -0.0283 in Table 2. Figure 4 portrays the estimated benefits of incremental suppression,

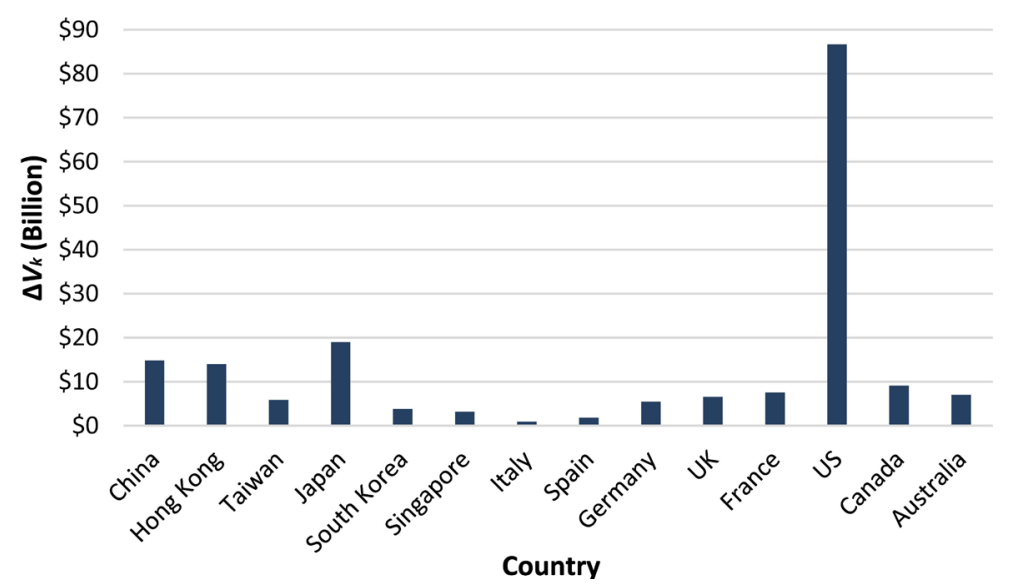

Notes:(1) The benefit calculation is based on Equations (1) and (2) in Section 2.1. (2) The elasticity estimates are those reported in Table 2.

Figure 4. Estimated benefits (based on MSCI total market indices' capitalization) of a hypothetical $10 \%$ reduction in the number of cumulative confirmed cases. 
Table 3. Results from a panel data (fixed effects) analysis of MSCI total market index data based on 727 daily observations in the sample period of 01/21/2020-04/03/2020.

\begin{tabular}{|c|c|c|c|c|}
\hline Variable [coefficient] & $\begin{array}{c}\text { Model 0: Equation } \\
\text { (3) that has varying } \\
\text { elasticities }\left(\alpha_{k} \neq \alpha\right) \\
\text { and includes fixed } \\
\text { effects }\end{array}$ & $\begin{array}{c}\text { Model } 1 \text { under } \\
H_{1} \text { : Identical } \\
\text { elasticity } \\
\left(\alpha_{k}=\alpha\right)\end{array}$ & $\begin{array}{c}\text { Model } 2 \\
\text { under } H_{2}: \text { No } \\
\text { fixed effects }\end{array}$ & $\begin{array}{l}\text { Model } 3 \text { under } H_{3} \text { : } \\
\text { Identical elasticity } \\
\left(\alpha_{k}=\alpha\right) \text { and no } \\
\text { fixed effects }\end{array}$ \\
\hline$R^{2}$ : within & 0.8460 & 0.8008 & & \\
\hline$R^{2}$ : between & 0.0019 & 0.3470 & & \\
\hline$R^{2}$ : overall & 0.0145 & 0.1046 & 0.8425 & 0.1361 \\
\hline $\ln (1+$ number of cumulative confirmed cases $):$ not country-specific $[\alpha]$ & & -0.0345 & & -0.1308 \\
\hline $\ln (1+$ number of cumulative confirmed cases $)$ : China $\left[\alpha_{1}\right]$ & -0.0219 & & -0.2539 & \\
\hline $\ln (1+$ number of cumulative confirmed cases $)$ : Hong Kong $\left[\alpha_{2}\right]$ & -0.0415 & & 0.4293 & \\
\hline $\ln (1+$ number of cumulative confirmed cases $)$ : Taiwan $\left[\alpha_{3}\right]$ & -0.0571 & & -0.2965 & \\
\hline $\ln (1+$ number of cumulative confirmed cases $)$ : Japan $\left[\alpha_{4}\right]$ & -0.0394 & & 0.1429 & \\
\hline $\ln (1+$ number of cumulative confirmed cases $)$ : Korea $\left[\alpha_{5}\right]$ & -0.0325 & & -0.1549 & \\
\hline $\ln (1+$ number of cumulative confirmed cases $):$ Singapore $\left[\alpha_{6}\right]$ & -0.0674 & & 0.1799 & \\
\hline $\ln (1+$ number of cumulative confirmed cases $)$ : Italy $\left[\alpha_{7}\right]$ & -0.0331 & & -0.1952 & \\
\hline $\ln (1+$ number of cumulative confirmed cases $):$ France $\left[\alpha_{8}\right]$ & -0.0385 & & 0.0239 & \\
\hline $\ln (1+$ number of cumulative confirmed cases $)$ : Germany $\left[\alpha_{9}\right]$ & -0.0382 & & 0.0292 & \\
\hline $\ln (1+$ number of cumulative confirmed cases $)$ : Spain $\left[\alpha_{10}\right]$ & -0.0337 & & -0.1604 & \\
\hline $\ln (1+$ number of cumulative confirmed cases $)$ : UK $\left[\alpha_{11}\right]$ & -0.0458 & & -0.0573 & \\
\hline $\ln (1+$ number of cumulative confirmed cases $):$ US $\left[\alpha_{12}\right]$ & -0.0287 & & 0.0854 & \\
\hline $\ln (1+$ number of cumulative confirmed cases $)$ : Canada $\left[\alpha_{13}\right]$ & -0.0539 & & 0.0117 & \\
\hline $\ln (1+$ number of cumulative confirmed cases $):$ Australia $\left[\alpha_{14}\right]$ & -0.0743 & & -0.0924 & \\
\hline$p$-value of the $F$-statistic statistic for testing $H_{m}$ for $m=1,2,3$ & & $<0.0001$ & $<0.0001$ & $<0.0001$ \\
\hline
\end{tabular}

Notes: 1 ) For brevity, this table omits the estimated intercept and fixed effects that are highly statistically significant $(p$-value $<0.01) .2)$ The CCC elasticities are labelled according to their continental locations: Asia's elasticities are $\alpha_{1}$ to $\alpha_{6}$, Europe's $\alpha_{7}$ to $\alpha_{11}$, North America's $\alpha_{12}$ and $\alpha_{13}$, and Australia's $\alpha_{14}$. 3) We use robust standard errors clustered by market that are heteroskedasticity-autocorrelation-consistent to determine the coefficient estimates' statistical significance. 4) Coefficient estimates in bold are statistically significant $(p$-value $<0.05)$ and have correct signs. Coefficients estimates in italic are statistically insignificant $(p$-value $>0.05)$ and have wrong signs. Coefficients estimates in italic are statistically significant $(p$-value $<0.05)$ and have wrong signs.

revealing 1) the estimated benefits in this figure are for the most part larger than those in Figure 3; and 2) the US estimated benefit based on total market capitalization is below US $\$ 100$ billion.

\section{Conclusion}

This paper proposes a stock-market-based approach to estimate the benefit of a hypothetical $10 \%$ reduction in cumulative confirmed cases due to incremental suppression of Covid-19 spread. The resulting estimated benefits for the 14 chosen stock markets range from US $\$ 0.76$ billion for Singapore to US $\$ 70$ billion for the US. The adjusted estimate for the US is up to US $\$ 100$ billion, owing to the $S$ \& P 500 index's $70-80 \%$ share of the US total market capitalization. Finally, we verify that our estimated benefits are empirically reasonable. 


\section{Conflicts of Interest}

The authors declare no conflicts of interest regarding the publication of this paper.

\section{References}

[1] WHO (2020) Situation Reports. https://www.who.int/emergencies/diseases/novel-coronavirus-2019/situation-reports

[2] Adda, J. (2016) Economic Activity and the Spread of Viral Diseases: Evidence from High Frequency Data. The Quarterly Journal of Economics, 131, 891-941. https://doi.org/10.1093/qje/qjw005

[3] Scherbina, A. (2020) Determining the Optimal Duration of the COVID-19 Suppression Policy: A Cost-Benefit Analysis.

https://www.aei.org/wp-content/uploads/2020/03/Scherbina-determining-the-opti mal-duration-WP 1.pdf

[4] CEA (2019) Mitigating the Impact of Pandemic Influenza through Vaccine Innovation. https://www.whitehouse.gov/wp-content/uploads/2019/09/Mitigating-the-Impact-o f-Pandemic-Influenza-through-Vaccine-Innovation.pdf

[5] Ramelli, S. and Wagner, A. (2020) What the Stock Market Tells Us about the Consequences of COVID-19.

https://voxeu.org/article/what-stock-market-tells-us-about-consequences-covid-19

[6] Elton, E.J., Gruber, M.J., Brown, S.J. and Goetzmann, W.H. (2014) Modern Portfolio Theory and Investment Analysis. John Wiley \& Sons, Hoboken, NJ.

[7] Davidson, R. and Mackinnon, J.G. (1993) Estimation and Inference in Econometrics. Oxford Press, New York.

[8] Im, K.S., Pesaran, M.H. and Shin, Y. (2003) Testing for Unit Roots in Heterogeneous Panels. Journal of Econometrics, 115, 53-74. https://doi.org/10.1016/S0304-4076(03)00092-7

[9] Wooldridge, J.M. (2010) Econometric Analysis of Cross Section and Panel Data. MIT Press, Cambridge.

[10] Nappani, S. and Washer, K.M. (2006) SARS: A Non-Event for Affected Countries' Stock Markets? Applied Financial Economics, 14, 1105-1110. https://doi.org/10.1080/0960310042000310579

[11] Ichev, R. and Marinč, M. (2018) Stock Prices and Geographic Proximity of Information: Evidence from the Ebola Outbreak. International Review of Financial Analysis, 56, 153-166. https://doi.org/10.1016/j.irfa.2017.12.004 